\title{
Targeted epidural catheter injection of polyethylene glycol hydrogel for repair of a spontaneous dural tear: a novel case report
}

\author{
Solomon Pearce, DO, ${ }^{1}$ Randall Henthorn, MD, ${ }^{2}$ and William Schueler, MD $^{3}$ \\ 1'Department of Pain Management, Mercy Health System Northwest Arkansas, Rogers, Arkansas; ${ }^{2}$ Department of Anesthesia \\ and Pain Management, University of Oklahoma College of Medicine, Oklahoma City, Oklahoma; and ${ }^{3}$ Department of \\ Neurosurgery, Northwestern Medicine Edward Neuroscience Institute, Naperville, Illinois
}

\begin{abstract}
The authors describe the novel approach of using a blunt-tipped catheter to repair a spontaneous dural tear. This case shows an effective percutaneous method of delivering dural sealant through an easily positioned catheter for the treatment of intracranial hypotension due to spontaneous CSF leakage.
\end{abstract}

http://thejns.org/doi/abs/10.3171/2015.6.SPINE1553

KEY WORDS spontaneous intracranial hypotension; cerebral spinal fluid leak; fibrin sealant; polyethylene glycol hydrogel; spontaneous dural tear; postural headache; epidural catheter; technique

$\mathrm{S}$ PONTANEOUS intracranial hypotension $(\mathrm{SIH})$ is a rare disorder caused by CSF leakage through a dural defect that characteristically produces postural headaches. ${ }^{1,3,10}$ Its prevalence is estimated between $2-5$ per 100,000 people..$^{10}$ Other symptoms may include neck pain and/or stiffness, facial numbness and weakness, nausea and vomiting, changes in hearing and/or balance, visual disturbances, and upper-limb radicular symptoms. ${ }^{9}$ Treatments range from bed rest, hydration, and abdominal binders to epidural blood patches, percutaneous transforaminal injections with fibrin sealant, CSF shunting, and open surgical repair., 4,6,7,10,12 Presented here is a novel technique for application of a dural sealant via a percutaneous epidural catheter directed to seal the defect.

\section{Case Report}

A 29-year-old woman with polycystic kidney disease and hypertension developed an acute pancephalic postural headache, neck pain, nausea, and vomiting. Initially she was treated as having an acute musculoskeletal strain, with NSAIDs, muscle relaxants, and opioid medication at both an urgent care facility and then 2 days later in an emergency room. Following a month with no improvement, she returned to the emergency department with ongoing postural headache, nausea, fatigue, and photophobia. MRI revealed diffuse pachymeningeal enhancement and thickening surrounding the brain and spinal cord. CT myelography revealed a right-sided T12-L1, 2-mm dural tear with ongoing CSF leakage (Fig. 1).

A fluoroscopically guided $30-\mathrm{ml}$ epidural blood patch was performed, which resolved her symptoms for 4 days. Upon return of her postural headache, a second blood patch was performed, which had similar temporary symptomatic relief.

Next percutaneous application of dural sealant to the defect was selected in the hopes of achieving lasting symptomatic relief while avoiding an open surgical closure. Based on the patient's imaging findings, we believed that a blunt-tipped catheter approaching the defect from a distal entry point had the highest likelihood of delivering the sealant while posing the least risk of exacerbating the dural tear.

The patient was prepared and draped in sterile fashion in the prone position with pillows under her abdomen to decrease her lumbar lordosis. The skin and projected subcutaneous path for the epidural needle was anesthetized 


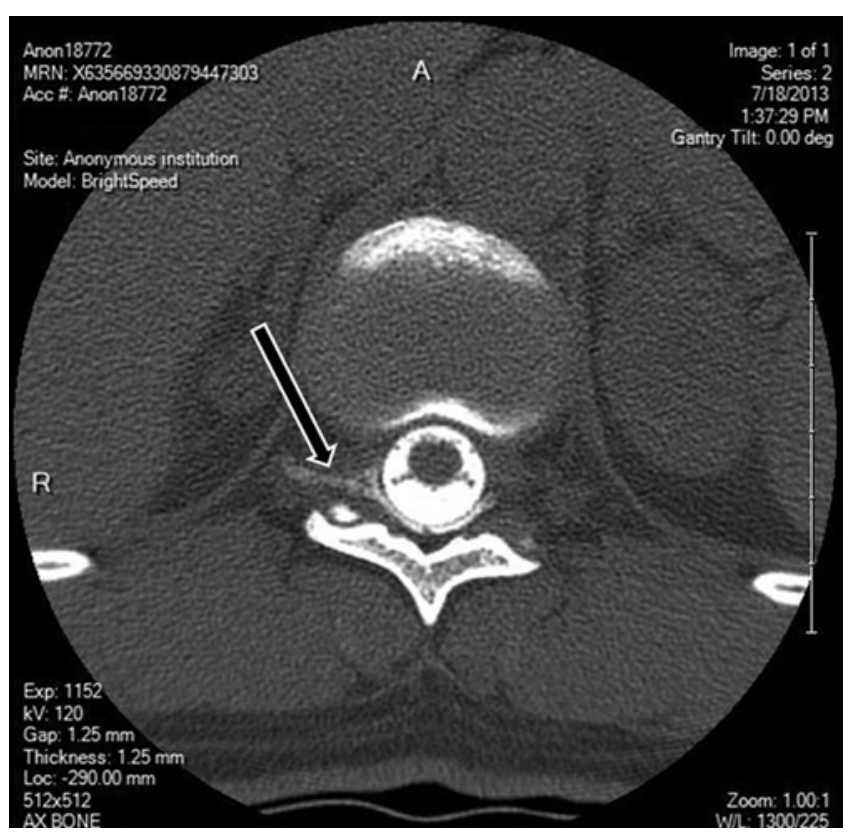

FIG. 1. Axial CT myelogram demonstrating T12-L1 right-sided dural defect with leakage of CSF. Arrow points to the CSF leak.

with $1 \%$ Xylocaine. A 16-gauge R.K. needle (Epimed) was passed from the medial edge of the L-3 pedicle into the dorsal epidural space at L1-2 using fluoroscopic guidance and loss-of-resistance technique. On removal of the stylet, CSF slowly dripped from the needle (as the epidural space was engorged with CSF, which had been leaking from the defect for the past month). A 19-gauge Brevi-XL catheter (Epimed) was guided to the right lateral recess of the epidural space. After negative aspiration for blood, $2 \mathrm{ml}$ of contrast revealed good epidural spread (without intrathecal spread on epidurogram) (Fig. 2). We then injected $4 \mathrm{ml}$ of the polyethylene glycol hydrogel dural sealant (DuraSeal) into the right lateral recess at the T12-L1 level. Immediately after injection of the dural sealant, the catheter was removed quickly with tip intact to avoid it becoming cemented in the spinal canal. Fluoroscopy revealed displacement of the initial contrast medium rostrally by the dural sealant at the T-12 and L-1 levels. Through the same needle a second catheter was introduced, and 2 $\mathrm{ml}$ of contrast material was injected below the level of the defect. The epidurogram demonstrated displacement and contrast void around the hardening dural sealant at the T12-L1 levels in the right lateral recess at the site of the defect (Fig. 3). After the second catheter and introducer needle were removed a Band-Aid was applied to the skin puncture site.

The patient was kept supine for 24 hours and then was discharged to home without restrictions as her headache had rapidly resolved. She experienced 3 days of postprocedure lower-extremity cramping, which resolved without treatment. She returned to her normal activities of daily living without requiring any medication for headache, nausea, spasm, or fatigue. She was followed up for the next 6 months and remained symptom free.

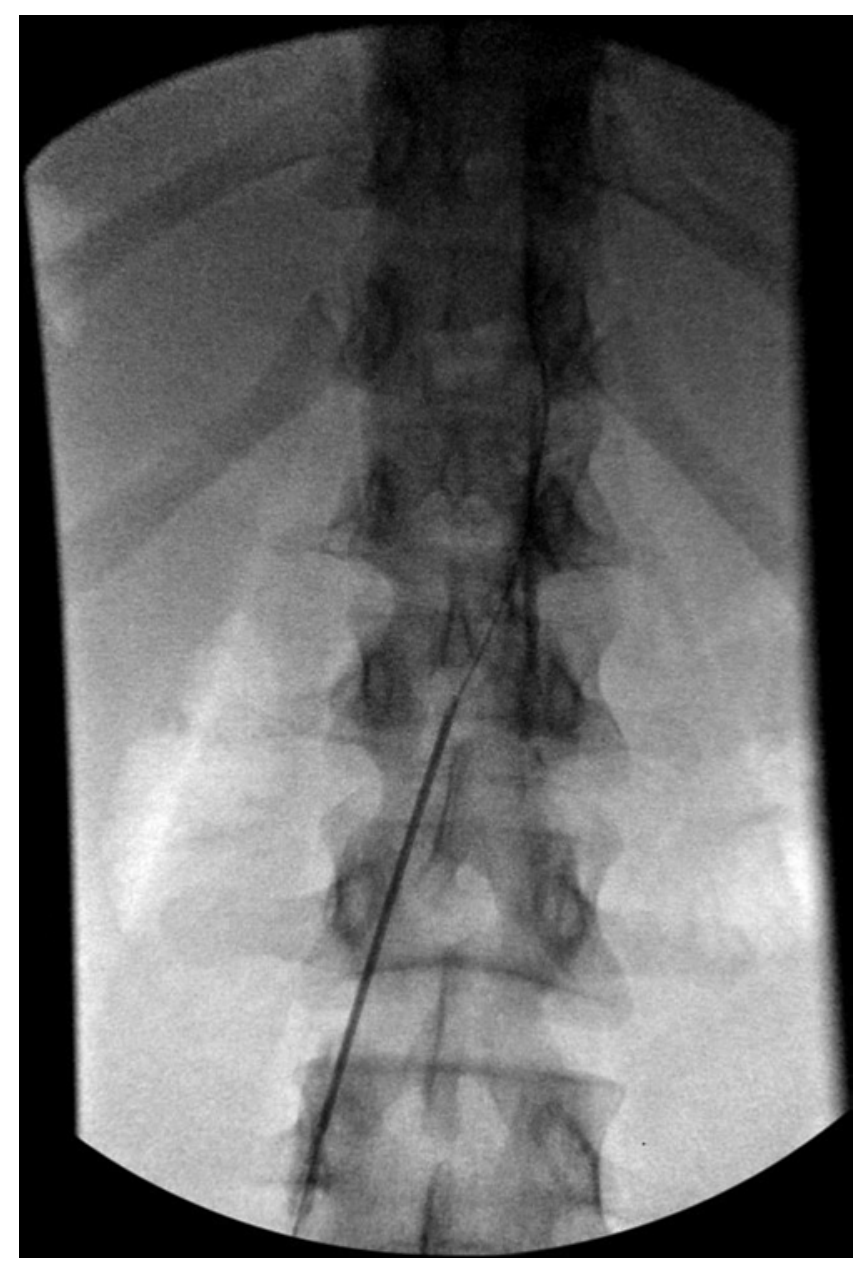

FIG. 2. Anterior-posterior fluoroscopic image demonstrating intralaminar needle placement at $L 1-2$ with the catheter directed to the right lateral recess at T12-L1 and good epidural spread of contrast.

\section{Discussion}

Four pathophysiological mechanisms proposed for $\mathrm{SIH}$ include intrinsic weakness of the meninges, spontaneous rupture of meningeal diverticula, dural tears from osteophyte shearing, and pressure effects from thoracic disc herniation..$^{3,10,15}$ Our patient's history of polycystic kidney disease (a collagen vascular disease) suggests intrinsic weakness of the meninges as the source of her dural defect, especially when imaging failed to show meningeal diverticula, osteophytes, or disc herniations. ${ }^{10}$

After more conservative treatments have failed, most treatment algorithms recommend moving on to blood patches, as we attempted in this case. ${ }^{1,10}$ Both of our patient's blood patches worked temporarily to relieve her headaches, but they ceased to be effective after 4 days. In studies of epidural blood patches, it has been shown that the cellular elements of the blood patch and its collagen deposition have begun to be removed by fibroblasts by the 4th day, making this one of the most susceptible times for patch failure. ${ }^{5}$

If blood patches are unsuccessful, algorithms then indicate that treatment proceed to dural sealants. ${ }^{1,10}$ Fibrin- 


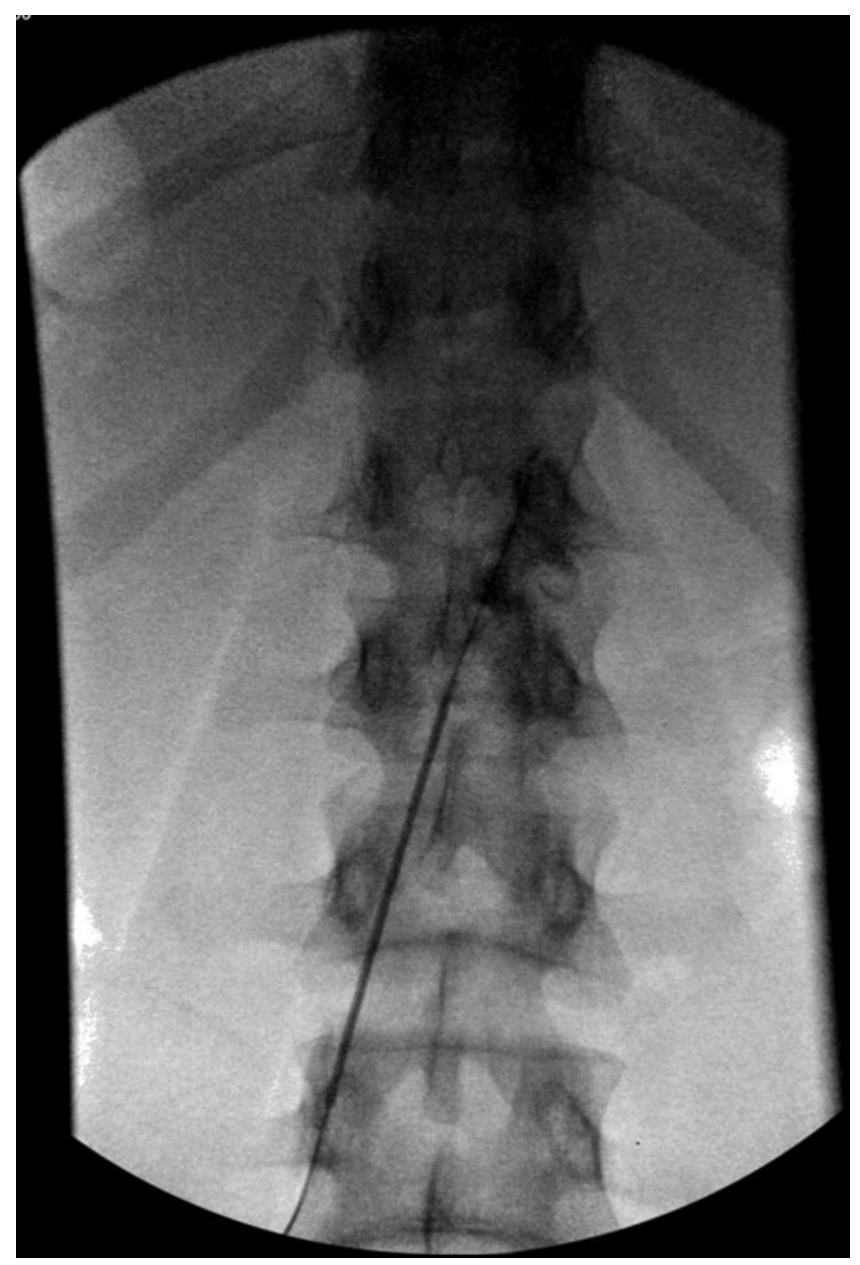

FIG. 3. Anterior-posterior fluoroscopic image demonstrating displacement and contrast void around the hardening dural sealant at the T12$\mathrm{L} 1$ levels in the right lateral recess.

based sealants are usually selected but carry a small risk of anaphylaxis and disease transmission, and they are fully absorbed by the body after 10-14 days (per Tisseel product insert). Similar synthetic products consisting of polyethylene glycol linked with trilysine last for 4-8 weeks before being hydrolyzed (Fig. 4). After the short duration of symptomatic relief with blood patches achieved in our patient, we decided to use the polyethylene glycol hydrogel (DuraSeal) in the hopes of resolving her symptoms while avoiding surgery.

Previous case reports have described the use of sharpneedle transforaminal injections of fibrin sealant. ${ }^{6,11}$ However, this approach may miss lesions located distant to the foramen, or it may have difficulty bypassing foraminal stenosis. Sharp needles may injure the dura, worsening the defect, or inadvertently cause vascular injections that sometimes produce spinal cord/brain injury. ${ }^{8}$ We chose to inject the dural sealant through a blunt-tipped, steerable epidural catheter (Epimed) that would allow specific targeting while posing a smaller risk of further worsening the defect.

Blood patch studies have indicated that it takes between

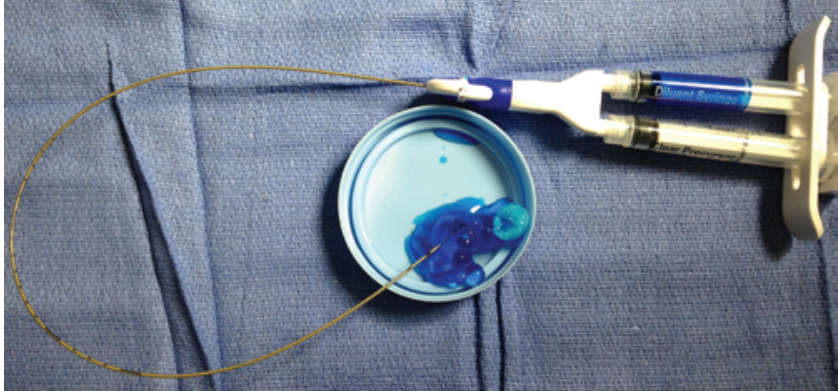

FIG. 4. Photograph of an in vitro test demonstrating easy delivery of polyethylene glycol hydrogel through an epidural catheter. Figure is available in color online only.

1.6 and $4 \mathrm{ml}$ of injected volume per vertebral body segment to establish a good patch., ${ }^{2,13,14}$ The volume of the hydrogel needed for our patient was estimated to be a total of $4 \mathrm{ml}$. As per instructions, after mixing each of its two precursor components there may be expansion from hydration by an additional $50 \%$. Thus, we estimated the internally injected hydrogel would possibly expand to $6 \mathrm{ml}$. This volume would then cover between 1.5 and 4 segments, $, 13,14$ allowing for extra coverage in case the patient's surrounding dura had similar areas vulnerable to tears. This volume was also similar to that which had previously been reported as successful in stopping SIH via a percutaneous approach. ${ }^{6,11}$ Also, imaging studies with this volume showed only mild displacement of the dural sac, without myelopathy. ${ }^{2,14}$

Spinal cord compression and vascular compromise are potential complications of spinal canal injections. ${ }^{8} \mathrm{In} \mathrm{SIH}$, the increased epidural space due to persistent CSF leakage allows for injection of sealant materials with less chance of pressure-related spinal cord injury., ${ }^{1,4,6,7,9-11}$ Although there have been no reported cases of persistent neurological injury associated with injection of dural sealants in SIH, means of performing immediate spinal decompression need to be available in case of progressive neurological deficits.

This case shows an effective percutaneous method of delivering dural sealant through an easily positioned catheter for the treatment of refractory intracranial hypotension due to spontaneous CSF leakage.

\section{References}

1. Amoozegar F, Guglielmin D, Hu W, Chan D, Becker WJ: Spontaneous intracranial hypotension: recommendations for management. Can J Neurol Sci 40:144-157, 2013

2. Beards SC, Jackson A, Griffiths AG, Horsman EL: Magnetic resonance imaging of extradural blood patches: appearances from $30 \mathrm{~min}$ to $18 \mathrm{~h}$. Br J Anaesth 71:182-188, 1993

3. Binder DK, Sarkissian V, Dillon WP, Weinstein PR: Spontaneous intracranial hypotension associated with transdural thoracic osteophyte reversed by primary dural repair. Case report. J Neurosurg Spine 2:614-618, 2005

4. Cousins MJ, Brazier D, Cook R: Intracranial hypotension caused by cervical cerebrospinal fluid leak: treatment with epidural blood patch. Anesth Analg 98:1794-1797, 2004

5. DiGiovanni AJ, Dunbar BS: Epidural injections of autologous blood for postlumbar-puncture headache. Anesth Analg 49:268-271, 1970 
6. Gladstone JP, Nelson K, Patel N, Dodick DW: Spontaneous CSF leak treated with percutaneous CT-guided fibrin glue. Neurology 64:1818-1819, 2005

7. Hayek SM, Fattouh M, Dews T, Kapural L, Malak O, Mekhail N: Successful treatment of spontaneous cerebrospinal fluid leak headache with fluoroscopically guided epidural blood patch: a report of four cases. Pain Med 4:373-378, 2003

8. Manchikanti L, Malla Y, Wargo BW, Cash KA, Pampati $\mathrm{V}$, Fellows B: A prospective evaluation of complications of 10,000 fluoroscopically directed epidural injections. Pain Physician 15:131-140, 2012

9. Mokri B: Spontaneous intracranial hypotension. Curr Pain Headache Rep 5:284-291, 2001

10. Schievink WI: Spontaneous spinal cerebrospinal fluid leaks and intracranial hypotension. JAMA 295:2286-2296, 2006

11. Schievink WI, Maya MM, Moser FM: Treatment of spontaneous intracranial hypotension with percutaneous placement of a fibrin sealant. Report of four cases. J Neurosurg 100:1098-1100, 2004

12. Schievink WI, Morreale VM, Atkinson JL, Meyer FB, Piepgras DG, Ebersold MJ: Surgical treatment of spontaneous spinal cerebrospinal fluid leaks. J Neurosurg 88:243-246, 1998

13. Szeinfeld M, Ihmeidan IH, Moser MM, Machado R, Klose KJ, Serafini AN: Epidural blood patch: evaluation of the volume and spread of blood injected into the epidural space. Anesthesiology 64:820-822, 1986
14. Vakharia SB, Thomas PS, Rosenbaum AE, Wasenko JJ, Fellows DG: Magnetic resonance imaging of cerebrospinal fluid leak and tamponade effect of blood patch in postdural puncture headache. Anesth Analg 84:585-590, 1997

15. Winter SC, Maartens NF, Anslow P, Teddy PJ: Spontaneous intracranial hypotension due to thoracic disc herniation. Case report. J Neurosurg 96 (3 Suppl):343-345, 2002

\section{Disclosure}

The authors report no conflict of interest concerning the materials or methods used in this study or the findings specified in this paper.

\section{Author Contributions}

Conception and design: all authors. Acquisition of data: Pearce, Henthorn. Analysis and interpretation of data: Pearce, Henthorn. Drafting the article: Pearce, Henthorn. Critically revising the article: Pearce, Henthorn. Reviewed submitted version of manuscript: all authors. Approved the final version of the manuscript on behalf of all authors: Pearce.

\section{Correspondence}

Solomon M. Pearce, Department of Pain Management, Mercy Health System Northwest Arkansas, 3101 SE 14th St., Bentonville, AR 72712. email: solomon.pearce@mercy.net. 